\title{
Interactive Value Production through Living Labs
}

\section{Imre Hronszky, Katalin Kovács}

Budapest University of Technology and Economics

Müegyetem rkp. 3-9, H-1111 Budapest, Hungary, hronszky@eik.bme.hu

ValDeal Innovations Zrt., Gyár u. 2, H-2040 Budaörs, Hungary, kovacs@ chic.hu

\begin{abstract}
Interactive, co-creative relations and collaboration of consumers, users and producers are quickly developing recently. Living Labs [LL] integrate users in the development process of new technologies as co-creators themselves. They have a special bridging role between market pull and technology push innovation and they realise some sort of concurrent innovation. LLs are an interactive search for new products/services in real life milieus together with users/consumers, without the mediation of marketing experts. They receive a different role. Our article highlights LLs first as providers of a collaborative working environment for users. This paper emphasises that LLs have a strong methodology and describes and assesses the "LL Harmonization cube". Further, it puts emphasis on the difference between a prospective notion of a $L L$ and the recent reality of the LL practice. Recent LLs mostly work at the end phase of the innovation 'chain'. The article secondly outlines what advantages LLs can bring for SMEs. The main added value of LLs for SMEs is that they provide for innovation services by integrating SMEs as users in a collaborative working environment that would otherwise not be available for them.
\end{abstract}

Keywords: Open innovation; Living Lab; Harmonization cube; SME involvement

\section{On Open Innovation, the Supply Side}

With some approach to history, in the majority of the $20^{\text {th }}$ Century the dynamic of innovation was 'linear', in-house, 'closed' innovation. Today, innovation is a networked phenomenon where the main issues happen in a globally connected world at the most varied intersections, for example at interactions among disciplines, interactions with the suppliers, interactions with consumers, etc. The innovation dynamic is thus full of feedback and often unavoidable repeated restarting of circles before a dynamic of iterative cycles is reached. Innovation is getting more and more open.

Linear innovation integrates the need and the demand sides very specifically. Linear innovation realizes a technological push, developed in the $R \& D$ 
department of the firm, answering some broad demand only. You can successfully realize it when different factors are in coincidence, among them a stable broad demand that can be satisfied by mass products, this is still partly true with drug production, further when the decisive expertise can be gathered and isolated in the lab of the firm, when consumers are passive in the process, etc. Proprietary relations, command and control organizational mode within firms, mass production, and stability of supply on the market were integrated into a working dynamic in the earlier period and were tought to be the only possible model of innovation dynamics. But nowadays, 'linear', 'closed' innovation could not be successfully, efficiently realized by even the biggest firms. This is so because it would be either inefficient, or losing time or impossible to financing. The Ford $\mathrm{T}$ phenomenon may be the icon of closed production system with some product that could successfully count on some huge, stable, undemanding consumer layer. Henry Ford did not aim at the innovation of his product. Two generations later, until the early 90s, IBM can be seen as icon of closed innovation. That system integrated innovation vertically into the production and distribution value chain.

Relying on experts inside the huge firm, the R\&D department "within the walls" was the model for managing innovation in the second half of the last century. That was complemented with some stable co-operation forms, such as co-operation with some university labs. First customization efforts were supported by this structure. For a number of reasons that model definitely ceased to work appropriately at the end of the millennium. Among the numerous factors leading to its inappropriateness, first of all we mention the changes on the demand side, around the emerging need for individualization of the commodities for not only thin layers of customers. When the individualized needs of customers became to be taken into account, as far as possible, the relation between the knowledge and orientation in the R\&D departments and the concentration on users imagined by them, became more and more inappropriate. It is possible to say that a special sort of democratization started with this. But this inappropriateness is still partly preserved in practice, notwithstanding the huge development of marketing. [We have no place here to emphasize how immense new roles are being acquired by internet-based marketing and marketing research and integrated with long tail distribution based vendor activity, and how it revolutionizes the business. All this is most important. But we try in this short article to put the emphasis on the fullfledged interactive relation between the producer and consumers in the LLs.]

This customization tendency was coincided with the massification of educated layers, who could in principle provide that expertise needed by a firm that was unable to find in its R\&D department. In addition, the potential of knowledge spin-offs multiplied quickly. Some possibility for a very strong supply of experts from outside and expertise from users emerged by the end of the millennium. Expertise was rather rare earlier and transactions costs to utilize expertise from the outside seemed or proved to be too costly. While integrating the R\&D department into the vertical value chain had been justifiable both by transaction costs and 
human relations considerations from the early $20 \mathrm{~s}$ in the $20^{\text {th }}$ Century, and while it had been more efficient to integrate $R \& D$ internally rather than looking for expertise outside, under these conditions, ironically, at the end of the $20^{\text {th }}$ Century it started to become more efficient to follow the reverse path and to give up this vertical integration for a much more 'horizontal', open one. Changing vertical integration of [a part of] $R \& D$ for radically changing the search for expertise on the globalizing market and involving customers as a kind of producer as well, based on their special user expertise, started to become a good alternative. The internet, as an enabling medium, has an especially important role in this transformation.

This new possibility is termed 'open innovation'. In the globalizing environment every agent moving on the innovation scene has to try, in its own interest, to rely on, explore and exploit the disproportionally bigger knowledge base outside any firm. Henry Chesbrough termed a part of this new phenomenon 'open innovation' in 2003 and elegantly provided important knowledge of the changes, in which, in issues of $R \& D \& I$, the walls of the firms are getting more and more interpenetrable. The flow is really two directional. While we have numerous examples of when firms earlier tried to obtain and at least to keep on the shelf a lot of patents without any intention to realize them, but in this way hindering rivals from getting access to them at least, and counted stopped alternatives in their innovation funnel as unavoidable costs of innovation, many firms, by now, not only regularly outsource their R\&D\&I tasks but also make marketable their unrealized innovative ideas and development alternatives, looking in that way for some additional revenue. With regularly in-sourcing and outsourcing innovation tasks putting them in the globalizing marketplace, a new type of managing innovation emerges. Competition is supplemented by co-operation in this case on a market base, and becomes different from pure rivalry. Market-based worldwide co-operation has become essential in the competition for innovation. This is further complicated by open source activities financed by big firms in which research results are made open, even for competitors or together realized by competitors, in the hope of using the results for different targets. In addition, for example, some sorts in the open source movement and wikinomics [commons based peer production] are non-market based forms of co-operation. Actually, all these things are 'open' innovations.

Chesbrough introduced the fortunate term 'open innovation' in his path-breaking book in 2003 [9] but concentrated on the market based interactions. He concentrated on the specificities of the globalizing R\&D\&I market in which especially outsourcing the tasks, buying and selling ideas, prototypes or semi-final products started to become decisive constructed advantage in the global competition race. His main message was that, first of all, an appropriate business model is essential to realizing this possible advantage. 


\section{On Open Innovation, the Demand Side}

Chesbrough originally concentrated on product and production development and conceptualized the open market as B2B interaction, the division of labour among firms. The reasons for both limitations made by him at that time are already over, for analysis as well. Chesbrough himself has by now turned his attention from product innovation to service innovation [10]. He identifies service innovation as the escape route from the global 'commodity trap', the complex effect of the tendency that results from the interaction of diversification of products, of the moving of the production to countries where the wage is low and shortening of time products have on the market. Open service innovation is offered as a solution.

By responding to the constraints and opportunities of the changing innovation dynamic, many firms become networked in their innovation dynamic too. Gigantic firms such as the leading firms in aerospace industry move toward the realization of the vision that their strength is the ability to develop an ecology of a very far reaching division of labour with very different suppliers, and their basic core competence is the ability to manage the collaboration. What about the consumers?

Mass customization was a pioneering step 30-40 years ago in most developed countries. The current challenge is formulated, based on some practical cases already, by the late Prahalad and his followers as 'personalizing consumer experience'. [3] In a world of the personalized consumer experience, the role of the firms is profoundly changing. In the developing ecology, producers and consumers mutually provide an enabling environment to each other.

Concerning the involvement of consumers/users, one has to consider that product development could be, up to a limit, imagined for 'virtual users', as it was imagined simply within the firm walls for a long time in the history of industrial society, and only gradually was market research included as correction tool when the product, less the service needs became more individualized. But service innovation may work much less than product innovation without interaction with real users, without taking into account their individualizing needs. The notorious need for 'a hole in the wall' [Peter Drucker] can, of course, not only be satisfied by choosing from a much richer offering then by becoming proprietor of some drilling machine but the consumer may know much more about her contextual need situation than any producer. In a lot of cases, only s/he may deepest know the target and some essential conditions to reach it at her local place. One way to realize an interactive relationship is through utilizing the immense new possibilities of interactive marketing; another is realizing an LL relation as coproduction, interactive value production in the production process with the producers in a real-life situation, in its fullest developed form dominated by the user. 
It is a commonplace in management literature in the last twenty years that 'the customer is the king'. One way to learn about the customer is to get as much information as possible, or rather, to get the appropriate information about their behaviour through observation and experimentation with them. For our intentions in this article the important issue is that the customer is made an object of, in its developed form, an interactive, participative observation so that $\mathrm{s} /$ he herself gives the needed answers. We all know the great development over the last ten years, a strong revolution in marketing and marketing research both in terms of the social sciences and economics disciplines utilized and the changing technological base, the systematic exploitation of the Internet.

There are some limits here nevertheless, impossible to transcend. On the one side, experimenting with agents unavoidably preserves some reification even in the most open experimentation. So, not only at least some elements of the behaviour of the user unavoidably remain covered for the experimenting agents, but even the behaviour of the consumer as a whole may be distorted. On the other side, the mediation of the received information has its shortages, too. First of all, gathering information needs mediation by the marketing researchers. They have to translate for themselves first, and then to the producers, what they received as input from the customers. The difficulty can be indicated by referring to the 'stickiness' factor, including the tacit dimension, of the main bulk of knowledge users have. And of course, any observation situation preserves some sort of artificiality. Putting customers in an artificial milieu may have its unavoidable limiting effects on the possible information gathering. The question may be raised what could be perhaps a better basis for learning about the customer that can overcome, substitute or add to the information gathering process developed by market researchers. The 'artificiality' of situations when innovators initialize involvement of possible users to develop a new product in a co-evolutionary way, as is rather typical in software development, is quite a different issue from such experimentation when they interact with the developers-innovators only through mediation. We are interested in this short article in LLs. In them there is some trial to transcend this limit. Speculation on what the inherent limits of realizing LL relation between the producers and users are cannot be the object of this article, unfortunately.

The question of providing the most enabling place for customers to realize themselves is of the highest importance, for the consumer is really starting to become the decisive factor in the innovation race, and innovation capability is envisioned as the decisive strategic factor in the global economic competition. Trusted by the European Commission to assess the European tasks in the global competition race, in 2006, the Aho report [7] called for the EU to start to concentrate the entire societal-economic dynamic around innovation. In this, the demanding consumer is one of the essential elements in the productionconsumption circle. There is a growing general bad feeling in most developed countries over the last decade that the limitless availability of basic scientific 
knowledge and the nearly irresistible process of outsourcing of labour based on law wage into countries where labour is cheap, may finally result in losing the leading position of the recently most developed countries in global economic growth. One could add that the changing relation between the recently still leading countries and the BRICS, especially China and India, in the innovation race too, is about to become another very important factor in innovation, one worth being concerned about in the traditionally leading countries.

The typical suggestion for a solution to the challenge is traditional. It is to improve on the R\&D supply capabilities in product and production. There are other suggestions. Chesbrough, in 2011 [10], shifted attention to improving service innovation. Amar Bhidé [1] tries to moderate the starting panic and suggests as a 'consolation' turning more attention to weak places in the innovation chain. $\mathrm{He}$ emphasizes 'mid-level innovation', and taking advantage of innovating for the 'venturesome consumer'. He agrees that the race in outsourcing cheap labour or that basic science is within reach for everybody are not issues to reverse, but rather he assesses that this is less important for the global innovation race than is generally recognized in the literature. In his assessment, the main issue concerning global economic growth remains the competition in the markets of the most developed countries. A decisive turn to the 'venturesome consumer' is a decisive driver to preserve the position, he suggests. 'Venturesome consumers' may be ready to develop and identify new needs which are costly and require intensive R\&D\&I on the supply side. All this means critical important feedback as a driver in the 'innovation chain'; that is, concentrating on the further integration of the steadily emerging needs of the 'venturesome customers' inside the 'innovation chain', as soon as possible as a co-evolutionary dynamic of producers and consumers. With this we have a suggestion for solution to find one adequate microeconomic and management answer to the macroeconomic challenge of global economic growth for both the most developed and the developing countries.

Bhidé concentrates on 'venturesome customers' and narrows the focus on customers to rich customers. There is still some widespread misunderstanding that the realization of the growing market for poor consumers does not need their interactive involvement in the production process as users. We have no place here to outline how essential can be the interactive user involvement in this dynamic, as the successful practices, including LL trials for example in South-Africa or India, demonstrate, but just notice that "reverse innovation" is rapidly growing as a main innovation type. And Living Labs are quickly developing in interactive value production with poor consumers too.

Eric von Hippel believes that most of the innovative product and production technology ideas in history have been introduced not by producers and professional developers but by users. [6] Already a look at history makes it rational to think that concerning some unavoidable domestication of the mass products, i.e. accommodation of them to local conditions, users have been 
constrained to make their steady improvement efforts. Notwithstanding the uniformity overtone in mass-production, innovation in the diffusion phase has been unavoidably important. But Hippel also turns attention to a special group of users, the 'lead-users'. Interaction with them turns on its head the traditional relationship of producer and consumer, and the firm becomes the producer of the products envisioned by 'lead-users'. The history of innovation in the period of mass production was a period when the innovation dynamic leading to mass products was dominated by professional inventors whose activities were mainly subjected to and regulated by the joint effect of the supply side; and mass needs and the 'closed' form of innovation can be seen as the trial by the firm to get under control the innovation capability for producing mass products.

The recent overarching technological revolution strengthens the capability of 'professional inventors' in the labs of the firms but threatens as well with the consequence that it will provide a further growing stream of innovations for 'virtual users', as long as the old producer-consumer relation remains preserved. There is a very quickly growing trend to explore and exploit application possibilities in the recent technological revolution to utilize its potential. But costs and risks of R\&D\&I are also very quickly growing while the time component along the value 'chain' is getting shorter and shorter. Breakthrough innovation possibilities multiply in accelerating waves and with this innovations are turning to be a high risk [also high benefit] enterprise. With the acceleration of the race, there is much less time and space than in the period of mass production to thoroughly exploit new basic results of the exploration phase, because after some very partial exploitation, the recent dynamic forces companies to turn towards the exploitation of some newer basic results.

With this the decisive challenge, the bottleneck problem may become to 'meet' the 'customer'. This need may partly include that s/he may not want to change her consumption in the directions the supply side suggests. This can partly occur because those offerings may not meet existing or emerging [real] needs of [possible] users. That means that among the quickly growing abundance of new commodities [services included] there is a relatively narrow, perhaps even relatively narrowing range of those commodities which are really needed in the form they are offered. For example, the great majority of software is still not user friendly, as the EC estimates.

A double process emerges quite quickly. First, the importance of professional researchers and inventors inside the firm is balanced by those incomparably larger number of professional researchers and inventors who are outside but ready to cooperate. [This is recognized by Chesbrough in his first book, in 2003.] This process strengthens the supply side but may still threaten via the overproduction of not really needed products that consumers may later reject. The performances of open innovation realized this way are challenged by the need for essential inclusion of [possible] users and consumers in a new, integrated mechanism of research and innovation. Herewith, we have the challenge to realize the integration 
of the demand orientation of R\&D\&I in the innovation chain to balance the innovation dynamic, provided we understand both existing and emerging 'demands' as 'demand'.

The following figure, made after Donald Stokes 1997 [4], represents the place of 'use-inspired research' as a result of some integrating 'concurrent' activity. [A 'concurrent' activity solves the problem simultaneously from both sides. Stokes' perspective was to improve 'use-inspired research' by turning researchers consciously in this direction, but he himself did not speak about inclusion of open innovation, either in the form of innovation outside the walls of the firm or inclusion of interactive customers.]

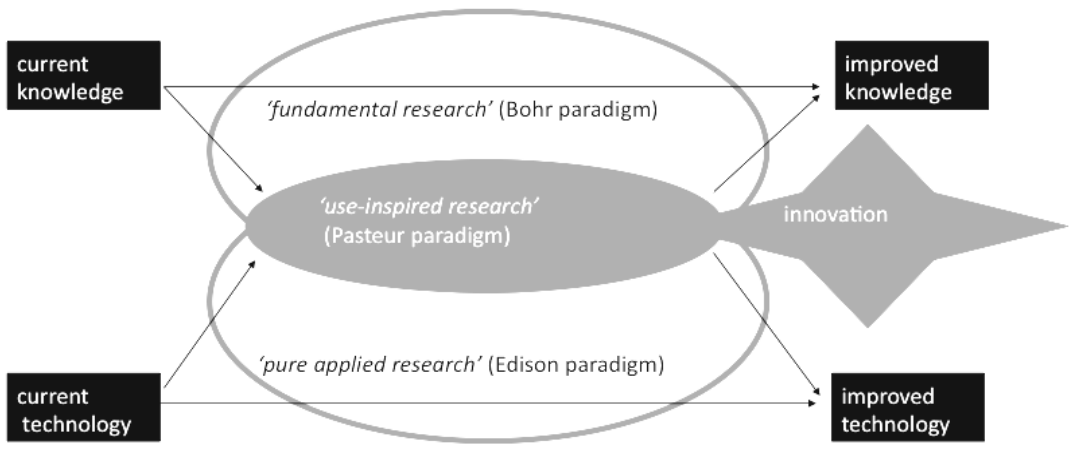

Figure 1

Use-inspired research [12]

A research dynamic involving 'use-inspired research' is the furthest element of inclusion of the 'demand side'. It is the inclusion as active participants of the possible users already in the first element of the innovation 'chain'. This is the realization of a co-evolutionary approach. In the course of the realization of this dynamic, a selection process of possible users is quite natural. It is important to see that, with emerging innovations attributing the usual role of the demand side, representing 'the visible demand of buyers' [12], will be misleading. This is extending the structure of incremental innovations to every innovation. We can place emerging demands on the demand side, still, or with high rationality, on the supply side and identify them as a special sort of push. It is rational to say that in the context of early co-creation with possible users a 'contextual push' based on needs and dreams of possible future users evolves [12]. This is different from the market pull, especially when the market is still very unripe. This 'contextual push' provides a substitute for the still missing demand side and turns to be the market demand with ripe products. The challenge we concentrate on is to realize the 'contextual push' as fully as is meaningful as early as possible. 


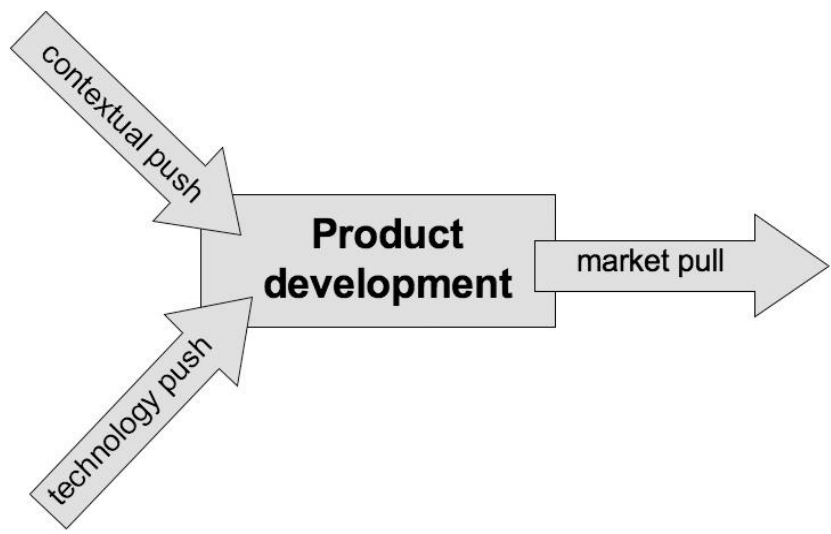

Figure 2

Product development and the relation of technology and 'contextual push' and market pull innovation

There is a growing belief that the chance of successful innovation moves from setting the task of innovating 'for the consumer' through moving to innovating 'with them' to the level of innovating 'by them'. The role of the firms is then to provide for an evolutionary environment. In this environment possible users, either other firms or human users, are enabled to develop their visions on their needs and can also find in firms the instruments to materialise the solutions that satisfy them. In this respect, we have the common denominator with lead user driven innovation, with open source based innovation, or with the famous pioneering, the LEGO Mindstorm issue. But it is important to see that there are rather different types of users, just as rather obstinate types of behaviour. They can be differentiated according to their possible roles in the innovation dynamics, more as pioneers or laggards, or their need for co-creation, etc.

\section{What is a Living Lab [LL]?}

One possibility of the answer is that an LL is an immediate, interactive, cocreative search, by active participation of users/consumers in the innovation process for new products/services in real life milieus. An LL form of co-operation means overcoming the mediation by market researchers by the immediate cooperation with the producers and the overcoming of the testing attitude by realizing a more symmetrical, co-creative relation. As with any other type of basic innovation of innovations, a working cycle of a production process in an LL ends in a mutually enabling change leading to some new 'product' [product or service] and some new societal infrastructure. These are embedded in the reproduction dynamic of a living network. 
It is worthwhile to turn to some comparison. In an often cited article, Pieter Ballon et al. [16] speak of a set of testing and experimentation platforms (TEP). They cover with their description the multiplicity of different test and design facilities. Among the different elements of TEP are real life user contexts, imagined by experts, with the purpose of observing the behaviour of those who are put in this environment. The observation aims at getting knowledge of the social and economic changes related to ICT developments. This knowledge is first of all expected to be used for making decisions among emerging technological alternatives by diminishing the uncertainty, in terms of acceptance by the consumers, surrounding their application in the real life milieu. "In addition to technological and innovation support, these facilities are set up for understanding and guiding the social and economic changes related to digital technologies and ICT developments. This refers to experimental settings, often imitating real life user contexts, where ICT developers and users interact and exchange views for optimal technological introduction." [16]

In the interpretation of Ballon et al. TEP provides the needed correction for some so called system failures. „In order to get a better grip on the innovatory use and how this can contribute to the technological landscape, these users are more and more investigated in direct contact with the technological prototype or service [that is being developed]. The 'virtual user' (Flichy, 1995) is replaced by the 'real' user in the innovation process."[16] This is most important but we have here the user still as an object for learning by experts when s/he interacts with developers in an as far as possible real milieu. This type of interaction is realized in a research milieu to learn from the interactive behaviour of the users by their observation. But it may give rise to immediate co-creation and aim at improving the innovation dynamic and turn into an LL relation among the participants.

LLs may lead much more in the direction of co-creation with the users than simply realising interactive test processes. An LL may offer some sort of service for possible users so that they can solve their existing problem by integrating themselves in this service milieu and use its service for their own purposes by transforming it. In this way, first they can produce an individual 'product' [in the overarching meaning of 'product', i.e. product or service], by way of application of their service but in an interactive process perhaps even led by the customer. Second the process of that 'customization' creates the possibility for a special type of generalization too, for the service provider. LL experiences provide them, to express it paradoxically, with non-standardisable "prototypes" of which working in real life milieus can be most rationally expected. LLs may provide here not just a qualified collaborative working environment to realise some individualized 'product', but also a learning milieu for interactive value creation of users with the service providers to serve for generalization. Better to say, two subclasses may perhaps be differentiated. In one subclass LL type collaboration in the dynamic of 'concurrent' innovation provides for over-bridging the pre-commercial gap, or improving any other previous elements of the 'innovation chain' for the producer. 
In the other subclass, realising a co-creation process first ends up in an individual product such as a changed city milieu like that realised in the Arabianrata project in Finland. [Arabianrata is a district of Helsinki that was reconstructed based on an LL project] Cases in this subclass can then serve as analogies for generalization but can not lead to standardizable prototypes. That is made by 'inductive' reasoning, unavoidably penetrated by expert opinion, provided by co-creation in the whole LL process including the users and further in the network of LLs everywhere where the first LL experience is intended to be extended.

It is important to make a projective concept of the LL, as a fully developed activity, serving as a vision for orientation; and it is also important to recognize the limits of the recent achievements of the existing LLs in reality. LLs are complex systems with a range of different levels in terms of user co-creativity. It is natural that numerous configurations recently classified as LLs are still at a quite low level. Concerning the phases of the 'innovation chain', LLs are recently most important in over-bridging the pre-commercial gap, and these LLs may prove to be most important in the future, too. But some others deserve the LL name for their activity in the last phase of the innovation dynamic only.

LLs as working units spread rather quickly. There were over 200 by 2011, mostly in Europe, and it can be expected that their number may grow to over 300 following the announcement of the fourth wave of ENoLL, the European Network of Living Labs membership enlargement in Budapest, in May 2011. Membership in ENoLL has a very important function when providing possibilities to utilize synergistic effects. Developing a flexible but well-developed set of methodologies is sine qua non for the lasting success of LLs, just as is providing a stable quality of the services that LLs can offer. Methodologies and quality assurance measures work for keeping and raising the quality of any LL, as well as the interoperability of different LLs.

\section{The Harmonization Cube Methodology and Quality Assurance of LLs}

European LLs have been unified by ENoLL into a network with the aim of strengthening collaboration and utilizing complementarities and resources among the members. There is a common methodology already to harmonize and exchange best practices of LLs developed by Mulder in 2007 [15] as the so called harmonization cube. In the Helsinki manifesto, which was communicated during the launch event of the first wave of LLs [November 2006], it is stated that, "This approach should ensure that common methodologies and tools are developed across Europe that support, stimulate and accelerate the innovation process It can be said that harmonization of LL methods and tools is key." [11] 
The harmonization cube defines the main interoperability elements from organizational, technical and contextual points of view, by the stages of LL maturity. It details the main elements of the evaluation methodology divided by the maturity stages of the LLs - and the direction for further development- the stages of setup, sustainability and scalability put on the vertical axe, in this order.
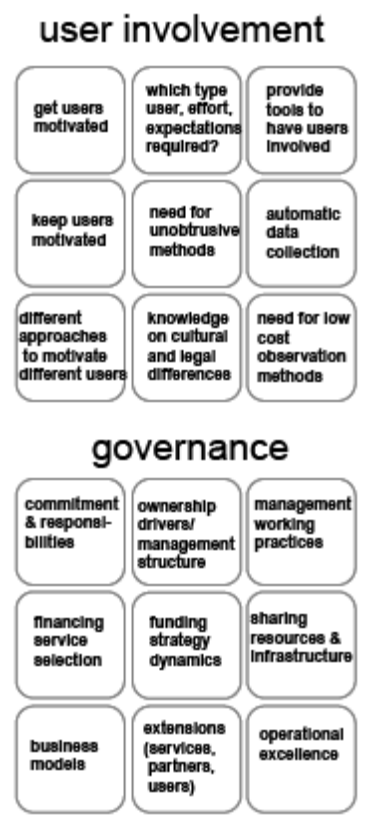

service creation
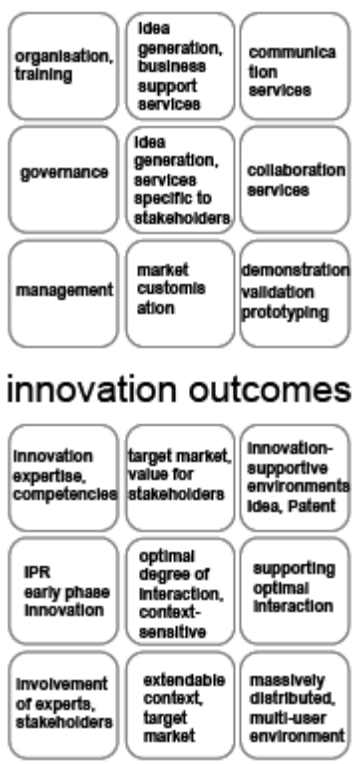

Figure 3

\section{infrastructure}

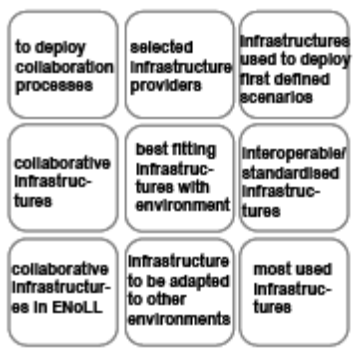

methods \& tools

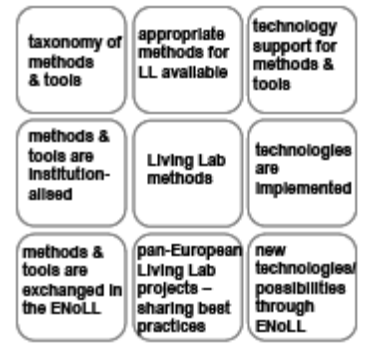

The elements of the harmonization cube [11]

The harmonization cube details the main elements that need to be considered in order to realise a more effective way of operation, interactive value creation, and interactive co-development for new products/services in the user's real life milieu.

The harmonization cube methodology focuses on the main elements that should be analyzed when evaluating LLs. The maturity of each element is measurable on a scale. The main elements of the interoperability cube assess the LL processes in detail, focusing on the main elements [11]. The key features of a LL are: immediate, interactive, co-creative user-involvement, iteratively involving all key actors across the stages. The methodology provides development opportunities for interactive, co-creative user-involvement methods. User involvement has different aspects that should be focused on, according to the maturity level of LLs. Methodical user involvement means firstly the identification of what the participating users are interested in, their behaviour, their roles, the identification of the user's motivations, the user's incentives, and the user's selection methods, e.g. by main segments or by interactions in the LL network. Once userinvolvement is successfully realized in the initial phases, then the main focus is 
gaining the users' interests by managing the community dynamic of the LL management, and this serves for the further development of the LL.

The service creation concept helps to analyze the way of collaboration and communication between the LL stakeholders, idea generation services, training services and management. The aim is to create common and efficient collaboration and communication among the stakeholders and strong partnerships between actors, and to organize the LLs coherently and effectively. A well developed, enabling infrastructure, especially the ICT infrastructure, is a key element in order to realise user involvement and LL management effectively. The issues of ownership, IT infrastructure architecture and its efficiency are measurement targets.

The governance pillar of the methodology consists of realizing the co-operation and interoperability between stakeholders, enhancing the level of openness and creating stability and balance in funding. The methodical analysis of an LL consists of determining and enhancing the adaptation possibilities of worldwide applicable innovation methodologies and their possible related collaboration methods, user involvement tools, standards and best practices. The final results of an LL's activity are measured by modifications in product development processes, lifecycle shortening, perhaps IP agreements, as well as the ability to respond interactively to continuously changing user needs.

\subsection{SME Involvement - an Additional Pillar to the Harmonization Cube}

The harmonization cube has six sides. Building on this concept, a spider diagram was introduced by the CO-LLABS project. To assess its importance, it adds an additional pillar focusing on SME involvement in LLs. ${ }^{1}$ SMEs can have both a user as well as a manufacturer role in an LL environment. Already existing LLs may provide the opportunity for SMEs to interactively test their products in advance, early in the development phase of the technology, by providing the service of customized testing according to the SME's unique requirements. As EC INFSO stated: "The underlying motivation is that LLs provide services to SMEs that otherwise would not be available to them. Focus is on how SMEs and their business partners can be involved in LLs in the best way in order to collaborate in open innovation, and on sharing experience among LLs initiatives and beyond as regards SME involvement in co-creation of LLs practices" [5]. The mentioned methodological pillars affect therefore the SMEs' business models. The main changes in business models derive from the necessary adaptation of user feedbacks and therefore change in the development processes in order to achieve a

CO-LLABS [Community-Based LLs to Enhance SMEs Innovation in Europe] project focuses on describing LL best practices. Modes of their operation and methods of user-involvement are analyzed focusing on the SMEs. 
more effective and easily variable infrastructure and working method. [Somewhat more can be found on the roles of LLs for SMEs from one author of this article in 'Open innovation for SMEs, 2010 [14]]

\subsection{The User-Involvement Side of the Interoperability Cube}

The key role of an LL, as already mentioned above, is to involve users effectively in the innovation process in order to make it more effective. In order to establish a productive co-creation process with the end users, appropriate user-involvement methods and tools should be chosen and adapted by the managers of LLs. We highlight the "user involvement" side of the harmonization cube in the following.

\begin{tabular}{|c|c|c|c|}
\hline SETUP & $\begin{array}{l}\text { get users } \\
\text { motivated }\end{array}$ & $\begin{array}{l}\text { which type of } \\
\text { user, effort, } \\
\text { expectations } \\
\text { required }\end{array}$ & $\begin{array}{l}\text { provide tools to } \\
\text { have users } \\
\text { involved }\end{array}$ \\
\hline SUSTAINABILITY & $\begin{array}{l}\text { keep users } \\
\text { motivated }\end{array}$ & $\begin{array}{l}\text { need for } \\
\text { unobtrusive } \\
\text { methods }\end{array}$ & $\begin{array}{l}\text { automatic data } \\
\text { collection }\end{array}$ \\
\hline \multirow[t]{2}{*}{ SCALABILITY } & $\begin{array}{c}\text { different } \\
\text { approaches to } \\
\text { motivate different } \\
\text { users }\end{array}$ & $\begin{array}{l}\text { knowledge on } \\
\text { cultural and legal } \\
\text { differences }\end{array}$ & $\begin{array}{l}\text { need for low cost } \\
\text { observation } \\
\text { methods }\end{array}$ \\
\hline & 离 & 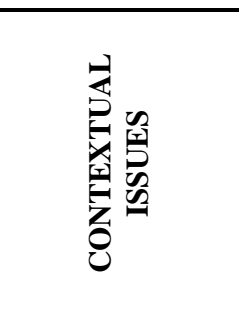 & 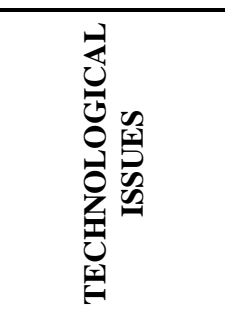 \\
\hline
\end{tabular}

Figure 4

The user-involvement side of the harmonization cube [11]

Based on the field of operation and the maturity of the LLs, different methods and tools should be considered and adapted, and the following main elements of the harmonization cube need to be negotiated. According to the user involvement side of the interoperability cube, three issues, organizational, contextual and technological, have to be taken into account when planning and adapting the userinvolvement methods and techniques.

The organizational issue of the user-involvement is first of all about the motivation of end users to participate in the innovation process of an LL. Based on the organization's maturity level, whether at setup, sustainability or scalability, the goal of motivation might differ. In the initial phase of an LL, the motivation techniques have the goal of getting users motivated. Getting users motivated means the collection of relevant users, winning their interest in the work of the 
LL, and making them enthusiastic about the user-involvement activity. In the more mature phase of a LL, when we have the motivated users actively participating in the innovation process, we should make efforts to sustain their interests and keep them motivated. In the last phase of LL maturity, we should focus on different users in different ways in order to keep them motivated.

The contextual issue of user-involvement is about creating the appropriate methods in order to set up a LL. It focuses on differentiating the users and is based on the groups; it deals with conducting analysis on their expectations in order to enhance their motivation level. In the sustainability phase of an LL, unobtrusive methods should be developed in order to keep the users motivated. In the scalability, the mature phase of an LL, even the users' cultural and legal differences should be considered.

The aim of the technological issues of user involvement is to provide tools for a reliable background for the co-creation activity. The method of user-involvement is mostly based on ICT technologies, providing a reliable background for data collection and the observation of all these processes at low cost.

\subsection{User Involvement Techniques}

There are several possible techniques to integrate users into the development process of products and services. The first method is to gain user opinions about a product or service, with a technique already used by marketing experts used interviews. Interviews can be differentiated by face-to-face, focus groups, informal conversation, a guided approach and even survey interviewing. Regarding LLs, preparing such an interview does not mean interactive userinvolvement. It is used to get an early opinion from possible later users about a product or service. The emergence of internet and ICT technologies provides a useful infrastructural background for user-manufacturer interaction on a higher level. Virtual communities like chat room sites or online forums are virtual places where people exchange messages with other persons or a group of people. By commenting on each other's posts regarding a product or service, new ideas and directions of development might occur.

Usability testing is the next phase of user involvement, with the aim of measuring how well people can use the products or services for their intended purposes in an as realistic situation as possible to discover errors and areas of needed improvement.

In the frame of the so called 'COLLABS' project, there was a marketing research, a survey conducted with existing LLs in order to get an overview of their userinvolvement methods. According to the survey, the most frequent methods for user involvement in the idea generation phase of products/services are interviews. According to the results, $90 \%$ of LLs use different kinds of interviews for this purpose, and even focus-group interviewing is used by $70 \%$ of LLs [13]. 
In the development phase of products/services, the dominant means of userinvolvement are the usability and prototype tests. Workshops with customers as well as virtual prototype tests are adopted by $30 \%$ to $40 \%$ of the LLs [13]. These results show that actual LLs are still far from the prospective concept, the ideal of LLs.

\section{Some Notes on LLs in Practice}

\subsection{The Aim of the Research}

In order to analyse the operation of LLs, and the added value they bring, further user involvement techniques used in practice were researched in an empirical study conducted by Katalin Kovács, focusing on the added value of LLs in the renewable energy business. ${ }^{2}$ For the purpose of this marketing type research, working LLs were analysed by executing internet search and, when necessary, semi-structured qualitative interviews based on the main elements of the harmonization cube. This research involved altogether 27 organizations using the "Living Lab" method in renewable energy innovation. We should emphasize that the LLs involved in the analysis target the development of sustainable, "green" buildings. Most of them also deal with the development of energy efficient technologies. The question and analysis categories were focused on the main added value of LLs, their role in renewable energy innovation and their contribution to the realisation of sustainable households. The core component of the LL analysis is about the role of users and the method of user involvement in the development process of technologies.

\subsection{The Activity and Relevance of LLs in Renewable Energy Innovation}

LLs are mostly initiated in the frame of government or EU programs. Their sustainability is established by the collaboration of companies, as the collaboration decreases their individual cost of development. Renewable energy LLs aim to decrease the fossil energy usage of buildings and to enhance energy efficiency.

Empirical research summarized in this paper is a part of the project executed in the frame of the fellowship program of the "IFZ - Inter-University Research Centre for Technology, Work and Culture", Graz in the 09.01.2012-30.04.2012. period. The research received funding from the Austrian Agency for International Cooperation in Education and Research, Centre for International Cooperation and Mobility, Austria (http://www.oead.at/). Project ID: ICM-2011-03428. Further results of the research executed in the frame of this fellowship program will be available in the journal "Environmental Innovation and Societal Transitions" probably in autumn 2013. 
Most of these LLs deal with implementing working prototypes of renewable energy technologies into homes in order to gain experience of the end-users from their normal living environment. The information about the renewable energy technologies are gained by sensors using the smart grid concepts in the LL building. LLs monitor the interactions of the users with the innovations at home, in order to provide information for the researchers to test and evaluate the innovations. In sum, the aim of renewable energy LLs is the development of sustainable, renewable energy innovations by monitoring the interaction of users/customers with the implemented technologies in their homes. The LLs intend to prototype, validate and co-create innovations and try to execute longitudinal testing as well. For this purpose they use so called LL "test houses", as well as attempt to install their technologies into homes over the long run.

\subsection{User Involvement Techniques}

The interactive co-creation with the end-users can be executed by the involvement of different groups of actors, involving also SMEs in the development process, on the supply side. The role of SMEs and research institutes from the construction industries is to provide inputs for testing and to stimulate discussion and creativity in such a way as to leave space for interactivity with the end-users. The role of LLs is then to organize co-creation with the users to gain information about the usage of new technologies in their normal, natural environment. Therefore, the main added value of LLs is the development and testing of technologies in this environment.

End users are therefore organized and involved to participate in the LLs in different ways and contexts according to the type of information companies would like to gain. When users are involved in the development process at an early stage, then interactive open innovation workshops are organized. End-users are recruited and motivated to participate, and LLs gather the opinion of users and their needs for new developments. Besides these interactive open innovation workshops, the interaction forms of LLs with end-users are mostly through interactive exhibitions of renewable energy technologies, where users can express their opinion and give feedback to the researchers. At the later stages of the development process, when a first prototype is already available, the co-development, co-creation and interaction can be executed interactively with the end users by using the technologies/prototypes every day in its normal working environment. Technologies are also tested in the homes in order to perform longitudinal research using observation equipment to collect the reports of the users.

Based on the interviews executed, the participation of end users and experts in LLs should be organized by taking into consideration their cultural background and their socio-economic context. The purpose of this is to enhance the amount of information gained for developing the technologies by using the LL model, as well as to ensure the engagement of a definite group on the renewable energy technologies. 


\subsection{The Effect of LLs on Renewable Energy Innovation}

As a result these homes, as LLs, can demonstrate significant carbon reduction. Mostly universities, innovation centres, SMEs providing technologies for testing, local councils and citizens collaborate together to interact and co-develop innovative technologies. The smart-grid concept also helps users to optimize their energy usage.

LLs are a possibility for SMEs as well as research institutes and multinational companies to demonstrate their latest developments in an interactive forum and exhibitions in order to get critical opinions from the immediate interaction of the experts of the relevant fields and the end-users. Companies may gain long-term advantages this way and open new target markets. The LL is a strategic possibility for targeting different market segments with different products developed cocreatively with the users. There is an example for this, as "Habitat" LL especially targets the communities of low-income in order to target them with developments meeting their needs and to improve their living environment and the energy efficiency of their house, by way of learning from them interactively in an LL environment.

Involving users as co-creators into the development process might also enhance engagement and raise awareness of the community towards renewable energy technologies. Therefore they have a specific role in enhancing the social acceptance of these technologies. As has been well demonstrated by several studies, one of the significant problems of enhancing the usage of renewable energy technologies is their gaining social acceptance.

\section{Conclusions}

Open innovation as a new type of division of labour is already a widespread, global reality. It leads to horizontally networked firms where the networking [inclusion in, exclusion from the network] is subjected to a global competition. Many sorts of interactive relationships with the customers, including LL type, interactive value creation in an integrated production process are also quickly developing. The move towards consumer dominance in the innovation dynamic is envisioned by different analysts. But they conceptualise this dominance rather differently. A rather projected vision of what an LL could be sees this dominance as the leading role of users in their co-operation in the production process in the real life milieu where the solution for them must actually function. While the LL method is very important for product development, it is even more important in envisioning and realising services.

The research results on LLs in the renewable energy industry show that LLs provide several types of added value in innovation; among other benefits, they strengthen the commitment of renewable energy users as well as the immediate interaction among the main actors in the renewable energy industry. This article also highlights the main user involvement techniques and their usage in the 
renewable energy industry at different stages of the development process. We hope that these research results, having taken into account the industry specificities, can be utilized in other branches of industry as well. The future of LLs depends on the ability to realize the prospective concept of LLs instead of only/re/naming more or less testing procedures as LLs as often occurs nowadays.

\section{References}

[1] Amar Bhidé: The Venturesome Economy, How Innovation Sustains Prosperity in a More Connected World, Princeton University Press, 2008

[2] Anna Stahlbröst: Forming future IT - The Living Lab Way of UserInvolvement, Ph.D dissertation, Lulea University of Technology, 2008

[3] C. K. Prahalad - M. S. Khrisnan: The New Age of Innovation, McGraw Hill Books, 2008

[4] Donald E. Stokes: Pasteur's Quadrant, Washington DC. The Brooking Institution, 1997

[5] EC INFSO: Living Labs for User-driven Open Innovation, An Overview of the Living Labs Methodology, Activities, Achievements, 2009, p. 19

[6] Eric von Hippel: Democratizing Innovation. MIT Press, Cambridge, 2005

[7] Esko Aho: Creating an Innovative Europe, Office for Official Publications of the European Communities, Luxembourg, 2006

[8] Hans Schaffers et al.: CO-LLABS Technical Report WP1, 2008, pp. 8-13

[9] Henry Chesbrough: Open Innovation: The New Imperative for Creating and Profiting from Technology. Boston, Harvard Business School Press, 2003

[10] Henry Chesbrough: Open Services Innovation, Jossey-Bass, San Francisco, 2011

[11] Ingrid Mulder, Daan Velthausz, Martijn Kriens: The Living Lab Harmonization Cube: Communicating Living Lab Essentials, eJOV Executive - The Electronic Journal for Virtual Organizations and Networks Volume 10, "Special Issue on Living Labs", November 2008, pp. 2-6

[12] Ingrid Mulder, Pieter Jan Stappers: Co-creating in Practice: Results and Challenges, Collaborative Innovation Emerging Technologies Environments and Communities, Proceedings, Leiden, 2009

[13] Jens Schumacher, Karin Feurstein: Living Labs - the User as Co-Creator; ICE Conference proceeding, Sophia-Antipolis, France, 2007, pp. 3-6

[14] Katalin Kovács: Open Innovation and SMEs, Living Lab Best Practices and the Role of SMEs in Interactive User-Involvement, ERENET [Entrepreneurship Research and Education Network of Central European Universities] Profile Issue 22, March 2011 
[15] Mulder, I., et al: Towards Harmonized Methods and Tools for Living Labs. Paper to be presented at e-Challenges, The Hague, The Netherlands, October 24-26, 2007

[16] Pieter Ballon et al: Test and Experimentation Platforms for Broadband Innovation, SMIT, Brussels, 2005 